\title{
THE EFFECTS OF US ECONOMIC AND FINANCIAL CRISES ON EURO AREA CONVERGENCE
}

\author{
FABIO C. BAGLIANO
}

CLAUDIO MORANA

Working paper No. 15 - September 2010 


\title{
The effects of US economic and financial crises on euro area convergence.
}

July 2010

\begin{abstract}
Fabio C. Bagliano
Dipartimento di Scienze Economiche e Finanziarie, Universita' di Torino(Italy) and Center for Research on Pensions and Welfare Policies (CeRP, Collegio Carlo Alberto, Moncalieri, Italy).

Electronic address: fabio.bagliano@unito.it.
\end{abstract}

\section{Claudio Morana}

Dipartimento di Scienze Economiche e Metodi Quantitativi, Università del Piemonte Orientale (Novara, Italy), International Centre for Economic Research (ICER, Torino), Center for Research on Pensions and Welfare Policies (CeRP, Collegio Carlo Alberto, Moncalieri, Italy).

Electronic address: claudio.morana@eco.unipmn.it.

\begin{abstract}
As economic and financial integration between the US and the euro area is strong, assessing whether the recent US crisis may affect the process of real and nominal convergence within the euro area is important. The paper addresses this issue in the framework of a large-scale open economy macroeconometric model, featuring 14 euro area member countries, the USA, and 35 advanced and emerging economies. The results point to a likely contribution of US economic and financial crises to real divergence in the euro area, potentially affecting first, second and third moments of the output growth distribution; on the other hand, implications for nominal convergence are less clearcut.
\end{abstract}

Keywords: Euro area convergence, Great Recession, financial crisis, economic crisis, factor vector autoregressive models.

JEL classification: C22; E32; F36

Acknowledgements: The paper was presented at the International Conference on "The Economic Crisis and the Process of European Integration”, The European Parliament, Brussels, 2 June 2010. The authors are grateful to conference participants for useful comments. The paper is forthcoming in W. Meeusen (ed.), The Economic Crisis and Euro Area Integration, Edward Elgar, UK, 2010. 


\section{Introduction}

Since the 1980s the European economy has undergone a progressive process of economic integration, involving both real and financial markets. This process has not been monotone, with the main stages marked by the introduction of the European Exchange Rate Mechanism (ERM) in March 1979, the ratification of the Maastricht Treaty in November 1993, and the start of the Economic and Monetary Union (EMU) in January 1999. Many studies have approached the issue from different perspectives, focusing on business cycle synchronization, inflation convergence and persistence, and financial markets integration. Though the available empirical evidence is not fully clear-cut, the finding of a stronger comovement in real and financial variables across euro area countries over the 1990s is fairly robust. Yet, so far EMU does not seem to have contributed to further increasing euro area economic and financial integration, relatively to pre-EMU levels. For instance, as regards to real convergence and the existence of a euro area business cycle, the evidence suggests that business cycle synchronization across euro area countries is still weak (de Haan et al., 2008, Camacho et al., 2005), concerning subsets of countries rather than the whole area (Aguiar-Contraria and Soares, 2009; Mink et. al., 2007; Giannone et al., 2009) ${ }^{1}$, with stronger regional than international coordination (Montoya and de Haan, 2007). International trade emerges as one of the key sources of euro area business cycle synchronization (Bower and Guillemineau, 2006), with a positive effect also on nominal convergence (Honohan and Lane, 2003). Convergence in inflation trends seems to have occurred within the euro area, though persistent inflation differentials remain, due to cyclical dynamics (Cavallero 2010, Angeloni and Hermann 2004). Evidence of recent divergence in inflation rates has been provided by Busetti et al. (2007).

Moreover, financial market integration, while benefiting at least in the aftermath of the EMU from the elimination of currency risk (Fratzscher et al., 2002), leading to a decrease in stock market volatility for the most volatile markets of the euro zone, i.e. Italy and Spain, relative to the least volatile ones, i.e. France and Germany (Morana and Beltratti, 2002), as well as to a reduction in the equity home bias for portfolios owned by European institutional investors (Adam et al., 2002), would be still in progress as, for instance, market participation of households across euro zone countries is still heterogeneous (Guiso et al., 2003). Actually, the degree of stock market integration could have even decreased in the last few years relative to the 1990s, as stock markets comovements appear to be stronger for subsets of countries rather than for the whole area (Morana, 2010).

Since economic and financial integration between the euro area and the US is strong (Giannone et al., 2009; Morana, 2010), it is likely that the ongoing crisis, that heavily hit also the US economy, may have had an impact on the process of convergence in the euro area. This is consistent with the fact that symmetric shocks may have different effects across countries, according to the countryspecific degree of shock persistence. The convergence process should imply both a progressive reduction in the cross-country dispersion about the mean/median euro-area value of various macroeconomic indicators, as well as a more symmetric cross-sectional distribution. To provide a first look at the evidence, Figure 1 depicts the recent behaviour (2007-2009) of the distribution of several macroeconomic variables across 14 euro-area countries ${ }^{2}$, showing that the crisis has so far had quite a deep impact on euro-area economic activity and some effects on its cross-sectional dispersion as well. In 2009 median GDP growth became negative (-3.6\%), with a cross-sectional distribution featuring negative skewness and increased dispersion with respect to the previous two years. Some changes in the cross-sectional distributions of the output gap, the inflation rate and the unemployment rate can also be detected. All variables show pronounced skeweness, and changes

\footnotetext{
1: For instance, Aguiar-Contraria and Soares (2009) find that Germany, Austria, France, Spain, the Netherlands, Belgium and Luxembourg would form the euro-core, while Portugal, Greece, Italy and Finland are in the periphery. Yet, the evidence in favour of upward trend is weak at most. See also Mink et al. (2007).

2: Each boxplot displays several elements of the distribution of each given variable across the euro-area countries: the mean (dot), the interquartile range (represented by the box, and capturing $50 \%$ of the data), and the median (line in the box).
} 
also in the dispersion around median values (-5.2\%, 0.2\% and 8.2\% in 2009 for the output gap, the inflation rate and the unemployment rate, respectively).

In the light of the above evidence, the paper investigates the linkages between the US and the euro-area economies over the 1980-2009 period, aiming at assessing whether spillovers of macroeconomic and financial shocks from the US may have affected the convergence process of nominal and real variables in the euro area. While there is a vast literature on the economic and financial convergence in the euro area, we are unaware of other papers which have so far dealt with the likely consequences of the US crisis on the euro area convergence process. Moreover, the paper innovates in terms of the depth and wideness of the analysis and econometric methodology, providing an accurate investigation of the euro area-US macro/finance interface. In addition to 14 euro-area member countries and the US, 35 additional economies, covering advanced and major emerging countries, have been considered, in order to set the analysis in a proper open economy framework. The econometric model then counts about 300 equations, considering key macroeconomic and financial variables, and is set in the factor vector autoregressive (F-VAR) framework.

The contribution of US crises to the euro-area convergence process has then been assessed by measuring the dynamic responses of key euro-area country macroeconomic variables to real and financial shocks originating in the US; the features of the cross sectional distribution of such dynamic responses over different horizons is then assessed, in order to gauge also some hints on the likely short- and medium-term consequences of the ongoing crisis.

The findings of the paper indeed point to a likely contribution of US real and financial factors to real divergence in the euro area; in fact, a slowdown in US economic activity may not only lead to a contraction in the first moment of the cross-sectional distribution of GDP growth in the euro area, but also to an increase in second and third moments. US financial factors may also contribute to the increase in dispersion and skewness of the euro area GDP growth distribution, but are less likely to affect its first moment. Differently, neither real nor financial US factors are likely to have affected the process of nominal convergence in the euro area during the current crisis, given the near independence of the euro area inflation rate distribution from the US real and financial cyclical dynamics. Not surprisingly, both real and financial US factors are found to be important for euro area financial convergence, consistently with the strong economic and financial integration of the two areas and the leading role of the US economy: destabilizing US financial conditions may have then contributed to destabilizing financial markets in the euro area. In particular, US excess liquidity, house and stock prices, would have contributed to euro area stock market fluctuations; moreover, the downturn in US GDP growth would have contributed to the contraction in euro area stock prices, as well as to the increase in volatility and downside risk for both house and stock prices.

The rest of the paper is organized as follows. The next section introduces the econometric methodology, while in section 3 the data and their properties are presented. Then, section 4 discusses the specification and estimation of the F-VAR model and shows the main results. Finally, conclusions are drawn in section 5.

\section{Econometric methodology}

The econometric model is composed of two sets of equations. The first one refers to the US economy (with variables collected in vector $\mathbf{X}_{t}$ ), while the second to the other $m$-1 non-US countries (collected in vector $\mathbf{Y}_{t}$ ). The joint dynamics of $q$ macroeconomic variables for each of the

$m$ countries of interest (in vector $\mathbf{Z}_{t}=\left[\begin{array}{ll}\mathbf{X}_{t} & \mathbf{Y}_{t}\end{array}\right]^{\prime}$ ) are modeled by means of the following F-VAR model: 


$$
\begin{aligned}
& \mathbf{F}_{t}=\boldsymbol{\Phi}(L) \mathbf{F}_{t-1}+\eta_{t} \\
& \mathbf{G}_{t}=\boldsymbol{\Psi}(L) \mathbf{G}_{t-1}+\zeta_{t} \\
& \left(\mathbf{Z}_{t}-\boldsymbol{\mu}_{t}\right)=\mathbf{\Lambda} \mathbf{F}_{t}+\boldsymbol{\Xi} \mathbf{G}_{t}+\mathbf{D}(L)\left(\mathbf{Z}_{t-1}-\boldsymbol{\mu}_{t-1}\right)+\mathbf{v}_{t}
\end{aligned}
$$

In (3) $\mathbf{Z}_{\mathrm{t}}$ is the $n \times 1$ stationary vector of variables of interest, with $n=m \times q$, and $\boldsymbol{\mu}_{t}=\left[\begin{array}{ll}\boldsymbol{\mu}_{t}^{X} & \boldsymbol{\mu}_{t}^{Y}\end{array}\right]^{\prime}$ is a $n \times 1$ vector of deterministic components, including an intercept term, and linear or non linear trends components. $\mathbf{F}_{t}$ is a $r \times 1$ vector of observed or unobserved common factors, generated by the autoregressive process in (2), where $\boldsymbol{\Phi}(L)$ is a $r \times r$ finite order matrix lag polynomial, and $\boldsymbol{\eta}_{t}$ is a vector of i.i.d shocks driving the $\mathbf{F}_{t}$ factors. $\mathbf{G}_{t}$ is a $s \times 1$ vector of non-US factors, generated by the autoregressive process in (2) where $\boldsymbol{\Psi}(L)$ is a $s \times s$ finite order matrix lag polynomial, and $\zeta_{t}$ is a vector of i.i.d. shocks driving the $\mathbf{G}_{t}$ factors. The effects of both sets of factors on the US and nonUS variables in $\mathbf{Z}_{t}$ is captured by the loading coefficients collected in the matrices $\Lambda=\left[\begin{array}{ll}\Lambda^{X} & \Lambda^{Y}\end{array}\right]^{\prime}$ and $\boldsymbol{\Xi}=\left[\begin{array}{ll}\boldsymbol{\Xi}^{X} & \boldsymbol{\Xi}^{Y}\end{array}\right]^{\prime}$ (of dimension $n \times r$ and $n \times s$, respectively). Finally, $\mathbf{D}(L)$ is a $n \times n$ finite order matrix lag polynomial, partitioned as

$$
\mathbf{D}(L)=\left[\begin{array}{cc}
\mathbf{D}_{X X}(L) & \mathbf{0} \\
q \times q & \underset{q \times(m-1) q}{ } \\
\mathbf{D}_{Y X}(L) & \underset{(m-1) q \times q}{\mathbf{D}_{Y Y}(L)}(L-1) \times q \times(m-1) \times q
\end{array}\right]
$$

with

$$
\mathbf{D}_{Y Y}(L)=\left[\begin{array}{cccc}
\underset{\mathbf{d}_{11}(L)}{q \times q} & \mathbf{0} & \cdots & \mathbf{0} \\
\mathbf{0} & \mathbf{d}_{22}(L) & \cdots & \mathbf{0} \\
\vdots & & \ddots & \vdots \\
\mathbf{0} & \mathbf{0} & \cdots & \mathbf{d}_{m-1 m-1}(L) \\
q \times q &
\end{array}\right]
$$

and $\mathbf{v}_{t}=\left[\begin{array}{ll}\mathbf{v}_{t}{ }^{X} & \mathbf{v}_{t}{ }^{Y}\end{array}\right]^{\prime}$ is the $n \times 1$ vector of reduced-form idiosyncratic (i.e. country-specific) i.i.d. disturbances. It is assumed that all polynomial matrices $\boldsymbol{\Phi}(L), \boldsymbol{\Psi}(L)$, and $\mathbf{D}(L)$ have all roots outside the unit circle. Moreover, $E\left[\eta_{j t} v_{i s}\right]=0, E\left[\eta_{j t} \zeta_{i s}\right]=0$, and $E\left[\zeta_{j t} v_{i s}\right]=0$ for all i,j,t,s.

The specification of the model has important implications for cross-country linkages: firstly, US idiosyncratic shocks $\left(\mathbf{v}_{t}^{X}\right)$ do not only affect the US (through), but also the other countries (through $\left.\mathbf{D}_{X X}(L)\right)$. Differently, non-US idiosyncratic disturbances $\left(\mathbf{v}_{t}{ }^{Y}\right)$ do not affect US variables, while only own-country linkages are relevant for the other countries $\left(\mathbf{D}_{Y Y}(L)\right.$ is block diagonal). The specification selected is then consistent with the view that the US play a leading role in the transmission of macroeconomic shocks, interpreting US macroeconomic dynamics in terms of global dynamics (see for instance Beltratti and Morana, 2010 and Bagliano and Morana, 2009); this however does not prevent interlinkages between the US and the other countries, which are parsimoniously described by means of the non-US factors $\mathbf{G}_{t}$. 
By substituting (1) and (2) into (3), the dynamic factor model can be written in standard vector autoregressive form as

$$
\left(\begin{array}{c}
\mathbf{F}_{t} \\
\mathbf{G}_{t} \\
\left(\mathbf{Z}_{t}-\boldsymbol{\mu}_{t}\right)
\end{array}\right)=\left(\begin{array}{ccc}
\boldsymbol{\Phi}(L) & \mathbf{0} & \mathbf{0} \\
\mathbf{0} & \boldsymbol{\Psi}(L) & \mathbf{0} \\
\boldsymbol{\Lambda} \boldsymbol{\Phi}(L) & \boldsymbol{\Xi} \boldsymbol{\Psi}(L) & \mathbf{D}(L)
\end{array}\right)\left(\begin{array}{c}
\mathbf{F}_{t-1} \\
\mathbf{G}_{t-1} \\
\left(\mathbf{Z}_{t-1}-\boldsymbol{\mu}_{t-1}\right)
\end{array}\right)+\left(\begin{array}{c}
\varepsilon_{t}^{F} \\
\varepsilon_{t}^{G} \\
\varepsilon_{t}^{Z}
\end{array}\right)
$$

where

$$
\left(\begin{array}{c}
\varepsilon_{t}^{F} \\
\varepsilon_{t}^{G} \\
\varepsilon_{t}^{Z}
\end{array}\right)=\left(\begin{array}{c}
\mathbf{I}_{r} \\
\mathbf{0} \\
\boldsymbol{\Lambda}
\end{array}\right) \boldsymbol{\eta}_{t}+\left(\begin{array}{c}
\mathbf{0} \\
\mathbf{I}_{s} \\
\mathbf{\Xi}
\end{array}\right) \zeta_{t}+\left(\begin{array}{c}
\mathbf{0} \\
\mathbf{0} \\
\mathbf{v}_{t}
\end{array}\right)
$$

or

$$
\mathbf{Z}_{t}^{*}=\mathbf{H}^{*}(L) \mathbf{Z}_{t-1}^{*}+\boldsymbol{\varepsilon}_{t}
$$

with $\mathbf{Z}_{t}^{*}=\left[\begin{array}{lll}\mathbf{F}_{t} & \mathbf{G}_{t} & \mathbf{Z}_{t}-\boldsymbol{\mu}_{t}\end{array}\right]^{\prime}$, and variance covariance matrix

$$
E\left[\boldsymbol{\varepsilon}_{t} \boldsymbol{\varepsilon}_{t}^{\prime}\right]=\boldsymbol{\Sigma}_{\varepsilon}=\left(\begin{array}{ccc}
\boldsymbol{\Sigma}_{\eta} & \mathbf{0} & \boldsymbol{\Sigma}_{\eta} \Lambda^{\prime} \\
\mathbf{0} & \boldsymbol{\Sigma}_{\zeta} & \boldsymbol{\Sigma}_{\zeta} \boldsymbol{\Xi}^{\prime} \\
\Lambda \boldsymbol{\Sigma}_{\eta} & \boldsymbol{\Xi} \boldsymbol{\Sigma}_{\zeta} & \Lambda \boldsymbol{\Sigma}_{\eta} \Lambda^{\prime}+\boldsymbol{\Xi}_{\zeta} \boldsymbol{\Xi}^{\prime}+\boldsymbol{\Sigma}_{v}
\end{array}\right)
$$

where $E\left[\boldsymbol{\eta}_{t} \boldsymbol{\eta}_{t}^{\prime}\right]=\boldsymbol{\Sigma}_{\eta}, E\left[\mathbf{v}_{t} \mathbf{v}_{t}^{\prime}\right]=\boldsymbol{\Sigma}_{v}$, and $E\left[\zeta_{t} \zeta_{t}^{\prime}\right]=\boldsymbol{\Sigma}_{\zeta}$. The inversion of the F-VAR form to obtain the reduced vector moving average (VMA) form for the $\mathbf{Z}_{t}^{*}$ process, as well as the identification of the structural shocks, is discussed in Bagliano and Morana (2010).

In our analysis, the impact of a change in the variables of interest $\left(\mathbf{X}_{t}, \mathbf{F}_{t}, \mathbf{G}_{t}\right)$ on the $\mathbf{Y}_{t}$ block is investigated by exploiting the reduced form VAR structure of the model

$$
\left(\mathbf{I}-\mathbf{D}_{Y Y}(L) L\right)\left(\mathbf{Y}_{t}-\boldsymbol{\mu}_{t}^{Y}\right)=\left(\begin{array}{lll}
\Lambda^{Y} \boldsymbol{\Phi}(L) & \boldsymbol{\Xi}^{Y} \boldsymbol{\Psi}(L) & \mathbf{D}_{Y X}(L)
\end{array}\right)\left(\begin{array}{c}
\mathbf{F}_{t-1} \\
\mathbf{G}_{t-1} \\
\mathbf{X}_{t-1}-\boldsymbol{\mu}_{t-1}^{X}
\end{array}\right)+\boldsymbol{\varepsilon}_{t}^{Y}
$$

and computing the dynamic multipliers, i.e.

$$
\left(\mathbf{Y}_{t}-\boldsymbol{\mu}_{t}^{Y}\right)=\mathbf{V}(L)\left(\begin{array}{c}
\mathbf{F}_{t-1} \\
\mathbf{G}_{t-1} \\
\mathbf{X}_{t-1}-\boldsymbol{\mu}_{t-1}^{X}
\end{array}\right)+\boldsymbol{\varepsilon}_{t}^{Y}
$$

where $\mathbf{V}(L)=\left(\mathbf{I}-\mathbf{D}_{Y Y}(L) L\right)^{-1}\left(\boldsymbol{\Lambda}^{Y} \boldsymbol{\Phi}(L) \quad \boldsymbol{\Xi}^{Y} \boldsymbol{\Psi}(L) \quad \mathbf{D}_{Y X}(L)\right)$. 
The latter is equivalent to the impulse response analysis carried out from the reduced form VMA representation, and is appropriate when the focus is on the impact of a change in a given forcing variable, say US GDP, independently of its underlying economic cause (i.e. a given structural shock), on the $\mathbf{Y}_{t}$ block. The F-VAR model is estimated by means of a consistent and efficient iterative procedure, also featuring the Granger and Jeon (2004) robust approach, yielding median estimates for all the parameters of interest, obtained through simulation with 1000 replications (see Bagliano and Morana, 2010 for details).

\section{The data}

We use seasonally adjusted quarterly macroeconomic time series data, over the period 1980:1 through 2009:1, for 14 euro area member states (Austria, Belgium, Finland, France, Germany, Greece, Ireland, Italy, Luxembourg, Netherlands, Portugal, Slovakia, Slovenia, Spain), the US, and 16 additional advanced economies (Australia, Canada, Czech Republic, Denmark, Hong Kong, Iceland, Israel, Japan, New Zealand, Norway, Singapore, South Korea, Sweden, Switzerland, Taiwan, United Kingdom), 5 additional advanced emerging economies (Brazil, Hungary, Mexico, Poland, South Africa), and 14 secondary emerging economies (Argentina, Chile, China, Colombia, India, Indonesia, Malaysia, Morocco, Pakistan, Peru, Philippines, Russia, Thailand, Turkey), for a total of 50 countries. ${ }^{3}$

The data set for euro area member countries consists of real GDP, the CPI all-items index, real bank loans to the private sector relative to GDP, the real short-term interest rate (either a 3-month interbank rate or a 3-month Treasury Bills rate, depending on availability), and real house and stock prices. Due to lack of data availability, housing prices have not been considered for Austria, Belgium, Greece, Luxembourg, Portugal, Slovakia, and Slovenia. A similar data set has also been employed for the remaining non-US countries (house prices are only available for few additional OECD countries, i.e. Australia, Canada, Japan, New Zealand, Denmark, Norway, Sweden, Switzerland, and the UK). All these variables are included in the $\mathbf{Y}_{t}$ vector.

Differently, the dataset for the US is larger and composed of real GDP, civilian employment, real private consumption, real private investment, fiscal deficit to GDP, current account deficit to GDP, CPI all items index, three-month Treasury Bills real rate, 10-year Federal government securities real rate, real house prices, the real effective exchange rate, real share prices (S\&P500). Few financial variables have also been included, in order to monitor the impact of the financial crisis; in particular, the economic/financial fragility index and the excess liquidity index proposed in Bagliano and Morana (2010). ${ }^{4}$

All the above variable enters in the vector $\mathbf{X}_{t}$. In order to keep the US-euro area spillover analysis manageable, and consistently with with previous work on the Great Recession, only a sub-set of US macroeconomic and financial factors has been selected for the computation of dynamic multipliers, namely GDP growth, excess liquidity, house and stock prices and an economic/financial fragility indicator. $^{5} \quad$ Finally, also crude oil price and primary commodities (excluding energy) price shocks,

\footnotetext{
3. US data are from FRED2; OECD countries data are from OECD Main Economic Indicators, integrated with IMF International Financial Statistics (bank loans series); data for the other countries are from IMF International Financial Statistics; house price series for OECD countries are taken from a non official OECD database (see http://www.olis.oecd.org/olis/2006doc.nsf/linkto/ECO-WKP\%282006\%293). The authors are grateful to P. Donati, S. Ejerskov, P. Benczur, M. Jensen for help with some of the data.

4: The economic/financial fragility index is computed as the first principal component extracted from the TED spread, the AGENCY spread, and the BAA-AAA corporate spread, providing an overall measure of credit/liquidity risk, stress in the mortgage market and risk appetite; the excess liquidity index is computed as the first principal component extracted from the M2 to GDP ratio and the total loans and leases at commercial banks to GDP ratio.

5: For instance, Bagliano and Morana (2010) find that the trade channel is the likely key transmission mechanism of the US economic crisis to the rest of the world, while US housing and stock prices and excess liquidity would have all
} 
computed following Hamilton (1996), have been considered and included in the vector F_\{t $\}$. In order to account for feedback effects from the world economy to the US economy, a single common non-US GDP growth factor, accounting for about $20 \%$ of total variance, has been extracted from the GDP growth series of the 37 countries for which data are available since 1980:1. ${ }^{6}$ This factor is included as the only element in the $\mathbf{G}_{t}$ vector.

As the econometric model is set in a stationary representation, data have been transformed ${ }^{7}$ accordingly; in particular, on the basis of the KPSS test (Kwiatkowski et al., 1992; Beckers et al., 2006), the weak stationarity, in deviation or not from a non linear deterministic trend component, modelled by means of the Gallant (1984) flexible functional form, i.e. $\mu_{t}=\mu+\mu_{1} t+\mu_{2} \sin (2 \pi t / T)+\mu_{3} \cos (2 \pi t / T)$, was established for the levels of the long-term and short-term real interest rates, the US current account to GDP ratio, the US public deficit to GDP ratio, and for the growth rates of all the remaining series; such deterministic terms are included in vector $\boldsymbol{\mu}_{t}{ }^{8}$

\section{US economic and financial shocks and euro area convergence dynamics}

The ordering of the variables in the econometric model is country by country and standard, from relatively "slow" to relatively "fast" moving variables. Then, the $\mathbf{X}_{t}$ vector for the US is ordered as follows: employment growth, real GDP growth, the Federal Deficit/GDP ratio, real private consumption growth, real private investment growth, the current account/GDP ratio, the CPI inflation rate, the excess liquidity index, the real three-month Treasury bills rate, the real ten-year Government Bonds rate, real house price returns, real effective exchange rate returns, real stock price returns, the financial fragility index. Similarly, the ordering for the $\mathbf{Y}_{t}$ vector, concerning the non-US countries, is: real GDP growth, CPI inflation, real excess credit growth, the real short-term rate, real house price returns (when available), and real stock price returns.

The dynamic specification of the econometric model has been selected by means of the BIC information criterion, pointing to an optimal first order F-VAR system. Assuming an own-variable diagonal structure for the corresponding elements of the $\mathrm{D}(\mathrm{L})$ matrix for the non-US countries, i.e. $\mathbf{D}_{Y Y}(L)$ diagonal, the euro area block then counts 77 equations, each containing 13 parameters, of which 1 for the lagged own variable, 5 are for the lagged US series, 3 for the lagged $\mathbf{F}_{t}$ and $\mathbf{G}_{t}$ series, and 4 for the deterministic component (including a constant, a linear trend and two nonlinear components, as described in data section). Similarly, for the remaining elements in the vector $\mathbf{Y}_{t}$. Differently, the 14 equations corresponding to the US block $\mathbf{X}_{t}$ contain 21 parameters each, of which 14 are for the lagged US series, 3 for the lagged $\mathbf{F}_{t}$ and $\mathbf{G}_{t}$ series, and 4 are for the deterministic component. The full system then counts 278 equations.

The impact of the US economic and financial shocks on euro area convergence dynamics is assessed by means of the properties of the cross-sectional distributions of the dynamic multipliers, measuring the response of euro area variables to a unitary change in the US variables included in (7), at two forecasting horizons, namely 6-month (short-term) and 3-year (medium-term). This is

contributed to the spillover of the US financial crisis to foreign countries. See also Levchenko et al. (2010) and Bems et al. (2010).

${ }^{6}$ : That is, the largest 18 OECD countries (Austria, Belgium, Denmark, Finland, France, Germany, Ireland, Italy, the Netherlands, Norway, Spain, Sweden, Switzerland, the UK, Australia, Canada, Japan and New Zealand), and a selection of the Latin American countries (Argentina, Brazil, Chile, Mexico, Peru), Asian countries (China, Hong Kong, Korea, Taiwan, Indonesia, Malaysia, Philippines, Singapore, Thailand, India, Pakistan, Turkey) and African countries (South Africa).

7: Out of the 14 euro area member countries, there are 7 countries for which 6 macroeconomic series are available, yielding 42 equations, and other 7 for which only 5 macroeconomic series are available, yielding 35 additional equations, for a total of 77 equations.

${ }^{8}$ : Details are not included for reasons of space, but are available upon request from the authors. 
consistent with the fact that a different degree of shock persistence in each country may lead a symmetric shock to have different effects across countries. The results reported in Table 1 and Figures 2-6 refer to the case of a unitary increase in the US variables; the effects of a unitary contraction in the US variables, which is the case of interest for some of the variables (output growth, for instance), can be read from the above Tables and plots by reversing the sign of the dynamic multipliers and associated statistics.

\subsection{The effects of US financial shocks}

In a boom-bust credit cycle interpretation of the recent crisis (see for instance, Bagliano and Morana, 2010), asset prices misalignments in the US housing and stock markets would have initially been fuelled by the availability of excess liquidity and low interest rates. ${ }^{9}$ The ballooning US trade deficit also likely contributed to the latter dynamics, as huge capital inflows were redirected from the Treasury and stocks markets to the housing market. Then, expected, but not materialized, housing price appreciation, would have lead the predatory lending mechanism to break down and to a generalized decline in asset prices and tight credit conditions, as financial institutions were forced into deleveraging and recapitalization. ${ }^{10}$ Due to the strong integration of US and euro area (EA) financial markets (Giannone et al., 2009; Morana, 2010), and the leading role of the US economy, the US financial cycle should have affected financial markets in the EA economy as well. In particular, the spillover of the US financial crisis to the EA and the rest of the world economy, is likely to have taken place through housing prices (see Bagliano and Morana, 2010; Beltratti and Morana, 2010), as well as excess liquidity and stock market dynamics.

Results concerning the impact of US financial shocks over our investigated sample (12980-2009) on the EA convergence process are collected in Table 1 (columns 2 through 5) and Figures 3 through 6, presenting descriptive statistics and corresponding box plots of the cross sections of dynamic responses of selected EA variables (GDP growth, inflation rate, real excess credit growth (the rate of change of real loans to GDP), real house price returns and real stock returns to various US disturbances over the 2- and 12-quarter time horizons. Several results are remarkable.

First, concerning the effects of the US financial shocks on real convergence, from Table 1 it can be noted that neither US excess liquidity, nor US housing or stock prices, or US economic/financial fragility, have a sizable impact on the median of the EA output growth distribution, neither in the short- nor the medium-term. Yet, in two cases, i.e. US housing prices and economic/financial fragility, the mean impact is sizable, and stronger in the short- $(-0.2 \%,-0.34 \%)$ than in the mediumterm (-0.15\% and $-0.26 \%)$; moreover, US financial factors do have an impact on the second and third moments of the EA output growth distribution, with a sizable increase in both dispersion ( $0.29 \%$ through $1.1 \%$ in the short-term, apart from stock prices) and skewness (-2 through -2.8 in the medium-term). Second, concerning the effects of US financial factors on nominal convergence, it can be noted that, apart from the medium-term impact of US excess liquidity and economic/financial fragility dynamics on the dispersion of the EA inflation rate cross-sectional distribution $(0.11 \%$ and $0.15 \%$, respectively), no sizable effects on first, second and third order moments of the inflation rate distribution can be noted.

Finally, concerning the impact of US financial factors on financial convergence within the EA, much richer interactions, of similar size in the short- and medium-term, can be noted. For instance, mean credit growth is sizably affected by US excess liquidity (-0.95\%), housing prices $(1.19 \%)$ and economic/financial conditions (2\%); the median impact is on the other hand somewhat smaller ($0.2 \%, 0.09 \%$ and $0.84 \%$, respectively); the impact on EA credit growth dispersion is also sizable (2.9\% through $3.3 \%$ ), as well as its impact on skewness (-2.4 through to 2.6). Similar findings hold

\footnotetext{
${ }^{9}$ : Recent empirical evidence for the US point out to a positive linkage between excess liquidity and house and stock prices, and to a negative linkage between interest rates and asset prices, with the latter being stronger than the former. See Bagliano and Morana (2010) for details.

${ }^{10}$ : See also Bagliano and Morana (2010) for significant interactions between housing and stock prices during the deleveraging process.
} 
for EA house price returns, as US excess liquidity, house prices and economic/financial fragility conditions sizably affect both the mean $(-0.41 \%, 0.49 \%,-0.21 \%$, respectively), median $(-0.69 \%$, $0.19 \%,-0.41 \%)$ and dispersion $(0.97 \%, 0.65 \%$ and $0.99 \%)$ of the EA housing price distribution, while the impact on skewness is more attenuated. Differently, US financial factors, stock returns included, are important for both the first and second moments of the distribution of EA stock returns, while their impact on skewness is more modest; for instance, the mean (median) impacts are $13.9 \%, 26.7 \%, 0.46 \%$, and $-7.65 \%(6.95 \%, 21.6 \%, 0.69 \%$, and $0.42 \%)$ for US excess liquidity, house prices, stock prices and economic/financial fragility conditions; the impact on dispersion is also large (20.1\%, 18.4\%, 2.14\%, 19.3\%).

Overall, US financial factors appear to be important determinants of euro area financial conditions, coherent with the strong integration of financial markets between the two countries: destabilizing US financial conditions may have then contributed to destabilizing euro area financial markets. In particular, US excess liquidity, house and stock prices, may have contributed to keep momentum in the euro-area stock markets during the boom phase of the credit cycle, yet contributing to market crash during deleveraging. Similarly, US house prices would have contributed to the cyclical phase in euro area house prices; the interactions across financial markets are complex, involving not only first moments, but also second and third moments.

\subsection{The effects of US GDP shocks}

There are different mechanisms that can explain how the US crisis originated in the financial sector then became an economic crisis, as both tight credit conditions and falling asset prices (wealth and Tobin's Q effects) may have constrained aggregate demand. ${ }^{11}$ A present value model, relating future developments in dividends and rents to output dynamics, can also account for second round effects, linking the slowdown in real activity to asset prices deflation. According to the results reported in Levchenko et al. (2010) and Bems et al. (2010), external demand can then be singled out as one of the key mechanisms through which the slowdown in US economic activity has been transmitted to the world economy. ${ }^{12}$

Results concerning the implications of US economic disturbances (captured in our framework by GDP shocks) for the convergence process in the euro area are collected in Table 1 (first column) and Figure 2. As for the effects of US recessions on the real convergence within the EA, it can be noted that a contraction in US GDP may lead to mean and median negative responses of EA GDP growth; the impact is in both cases anelastic, with a stronger point impact in the short-term (-0.34\% and $-0.13 \%)$ than in the medium-term $(-0.26 \%$ and $-0.11 \%)$; dispersion is also larger in the veryshort term $(0.55 \%)$ than in the medium-term $(0.42)$, while skewness is sizable, but similar at both horizons (about -2). Hence, the evidence does point to a role of the slowdown in US economic activity in the explanation of current real divergence in the EA; yet, apart from Greece (result not reported), cyclical responses still appear to be coordinated ${ }^{13}$; the divergence effect also appears to be slightly attenuated in the medium-term, due to a smaller dispersion. Moreover, concerning the effects of US recessions on EA nominal convergence, the evidence does not support any direct linkage between the state of the US business cycle and inflation dynamics in the EA: in fact, neither first, nor second or third moments of the cross-sectional inflation distribution do seem to have been influenced.

\footnotetext{
11: The empirical evidence is consistent with a linkage between asset prices and aggregate demand, pointing to an inelastic response of real activity, particularly for housing prices (Bagliano and Morana, 2010; Beltratti and Morana, 2010; Case et al., 2005; Chirinko et al., 2004; Carrol et al., 2006).

12: Levchenko et al. (2010) report a contraction in US imports of about $40 \%$ relatively to the level which would otherwise had occurred in a no-crisis environment. Moreover, according to Bems et al. (2010), real workd trade declined 15\% between 2008Q1 and 2009Q1, and 27\% of the fall in US GDP was trasmitted to foreign countries through a demand spillover, affecting durable goods in particular.

${ }^{13}$ : The negative correlation of the Greek business cycle with the euro area business cycle is a well established fact in the literature. See for instance Bower and Guilleminau (2006).
} 
Finally, concerning the effects of the contraction in US GDP on EA financial convergence, while for housing prices only the dispersion of the cross-sectional distribution seems to have been affected in both the short- and medium-term ( $0.88 \%$ and $1.69 \%$, respectively), more sizable effects can be detected for credit growth and stock returns; in both cases a contraction in US GDP is associated with negative mean and median responses, stronger in the medium-term (-0.34\% for credit; $-19.3 \%$ for stock returns) than in the short-term; the impact on dispersion and skewness is also notable for both stock returns $(20 \%,-1.07)$ and credit growth $(3.94 \%,-2.74)$. Hence, euro area financial convergence may have been affected by the slowdown in US GDP growth, particularly in the credit and the stock markets.

\section{Conclusions}

The aim of the paper is assessing whether the US economic and financial crises may have some effect on the process of real and nominal convergence in the euro area. The current paper addresses this issue by investigating the linkages between the US and the euro are countries for a large set of real and financial variables over the 1980-2009 period. In addition to 14 euro area member countries and the US, 35 additional countries, covering advanced and major emerging countries, have been included in the econometric model, set in the factor vector autoregressive (F-VAR) framework.

The findings of the paper indeed point to a likely contribution of US real and financial factors to real divergence in the euro area; in fact, a slowdown in US economic activity may not only lead to a contraction in the first moment of euro area GDP cross sectional distribution, but also to an increase in second and third moments; US financial factors may also contribute to the increase in dispersion and skewness of the euro area output growth distribution, but are less likely to affect the first moment of the distribution. Differently, neither real nor financial US factors are likely to have affected the process of nominal convergence in the euro area during the current crisis, given the near independence of the euro rate inflation distribution from the US real and financial cyclical dynamics. Both real and financial US factors are found to be important for euro area financial convergence, coherent with the strong economic and financial integration for the two areas and the leading role of the US economy: destabilizing US financial conditions may have then contributed to destabilizing euro area financial markets. In particular, US excess liquidity, house and stock prices, would have contributed to euro area stock market fluctuations, while US house prices would have contributed to euro area house prices cyclical dynamics; moreover, the downturn in US GDP growth would have contributed to the contraction in euro area stock prices, as well as to the increase in volatility and downside risk for both house and stock prices. Overall, the interactions between US and EA real and financial markets appear to be complex, involving not only first moments, but also second and third ones. 


\section{References}

Adam, K., T. Jappelli, A. Menichini, M. Padula and M. Pagano, 2002, Analyse, compare, and apply alternative indicators and monitoring methodologies to measure the evolution of capital markets integration in the European Union, Report to the European Commission, availabe at http://ec.europa.eu/internal_market/economic-reports/docs/020128_cap_mark_int_en.pdf.

Aguiar-Contraria, L. and M.J. Soares, 2009, Business cycle synchronization across the euro area: A wavelet analysis, University of Mimho, mimeo.

Angeloni, I. and M. Ehrmann, 2004, Euro area inflation differentials, ECB Working Paper Seris, no. 388.

Bagliano, F.C. and C. Morana, 2009, International macroeconomic dynamics: a factor vector autoregressive approach, Economic Modelling, Economic Modelling, 26, 432-444.

Bagliano, F.C. and C. Morana, 2010, The Great Recession: US economic dynamics and its spillover to the world economy, Universita' del Piemonte Orientale, mimeo.

Becker, R., W. Enders and J. Lee, 2006, A stationarity test in the presence of an unknown number of smooth breaks, Journal of Time Series Analysis, 27, 381-409.

Beltratti, A. and C. Morana, 2010, International house prices and macroeconomic fluctuations, Journal of Banking and Finance,34, 535-545.

Bems, R., L. Dedola and F. Smets, 2007, US imbalances - The role of technology and policy, Journal of International Money and Finance, 26, 523-545.

Bems, R., R.C. Johnson and K.-M. Yi, 2010, Demand spillovers and the collapse of trade during the Great Recession, IMF Working Paper Series, no. 10/142.

Bierens, H.J., 2000, Non parametric nonlinear cotrending analysis, with an application to interest and inflation in the United States, Journal of Business and Economic Statistics, 18, 323-37.

Bower, U. and C. Guilleminau, 2006, Determinants of business cycle synchronisation across euro area countries, ECB Working Paper Series, no. 587.

Busetti, F., Forni, L., Harvey, A., and F.Venditti, 2007, Inflation convergence and divergence within the european monetary union, International Journal of Central Banking, 3(2), 95-121.

Camacho, M., Perez-Quiros, G. and L. Saiz, 2005, Are European business cycles close enough to be just one? CEPR Workin Paper Series, no. 4824.

Cavallero, A., 2010, The convergence of inflation rates in the EU-12 area: A distribution dynamics approach, Univerista' del Piemonte Orientale, mimeo.

Carrol, C.D., M. Otsuka and J. Slacalek, 2006, How large is the housing wealth effect? A new approach, NBER Working Paper Series, no. 12746.

Case K.E., J.M. Quigley, and R.J. Shiller, 2005, Comparing wealth effects: The stock market versus the housing market, Advances in Macroeconomics, 5, art.1, 1-33.

Chirinko R.S., L.de Han and E. Sterken, 2004, Asset price shocks, real expenditures, and financial structure: a multicountry analysis, De Nederlansche Bank, Working Paper, no. 14/04..

de Haan, J., Inklaar, R. and R. Jong-a-Pin, 2008, Will business cycles in the euro area converge? A critical survey of empirical research, Journal of Economic Surveys, 234-273.

Fratzscher, M., 2002, Financial markets integration in Europe: On the effects of EMU on stock markets, International Journal of Finance and Economics, 7, 165-194.

Gallant, R., 1984, The Fourier flexible form, American Journal of Agicultural Economics, 66, 20408.

Giannone, D., Lenza, M. and L. Reichlin, 2009, Business cycles in the euro area, ECB Working Paper Series, no. 1010.

Granger, C.W. and Y. Jeon, 2004, Thick modelling, Economic Modelling, 21, 323-43.

Guiso, L., M. Haliassos, and T. Jappelli, 2003. Households stockholding in Europe, where do we stand and where do we go, Economic Policy, 36, 123-70.

Hamilton, J., 1996, This is what happened to the oil price-macroeconomy relationship, Journal of Monetary Economics, 38, 215-20. 
Honohan, P. and P.R. Lane, 2003, Divergent inflation rates in the EMU, Economic Policy, 18, 35794.

Kwiatkowski, D., P.C.B. Phillips, P. Schmidt and Y. Shin, 1992, Testing the null hypothesis of stationarity against the alternative of a unit root, Journal of Econometrics, 54, 159-78.

Levchenko, A.A., Lewis, L.T. and L.L. Tesar, 2010, The collapse of international trade during the 2008-2009 crisis: In search for the smoking gun, NBER Working Paper, no.16006.

Mink, M., Jacobs, J.P.A.M, and J. de Haan, 2007, Measuring synchronicity and co-movement of business cycles within an application to the euro area, 2007, CESIFO Working Paper Series, no. 2112.

Montoya, L.A. and J. de Haan, 2007, Regional business cycle synchronization in Europe, Burges European Economic Research Papers, no. 11.

Morana, C. and A. Beltratti, 2002, The effects of the introduction of the euro on European stock markets, Journal of Banking and Finance, 26, 2047-2064.

Morana, C., 2010, Realized mean-variance efficient portfolio selection and euro area stock market integration, Applied Financial Economics, 20, in press. 
Table 1: Descriptive statistics for the cross section of dynamic responses for euro area variables: mean, standard deviation, first, second (median) and third quartile, index of skewness and kurtosis.

\begin{tabular}{|c|c|c|c|c|c|c|c|c|c|c|c|}
\hline & \multicolumn{11}{|c|}{ US variables } \\
\hline \multirow[b]{2}{*}{ Responses } & & \multicolumn{2}{|l|}{ GDP } & \multicolumn{2}{|c|}{ excess liquidity } & \multicolumn{2}{|c|}{ house prices } & \multicolumn{2}{|c|}{ stock prices } & \multicolumn{2}{|c|}{ fragility index } \\
\hline & & 2 & 12 & 2 & 12 & 2 & 12 & 2 & 12 & 2 & 12 \\
\hline \multirow{7}{*}{ GDP } & mean & 0.336 & 0.264 & -0.081 & -0.057 & -0.198 & -0.152 & -0.007 & -0.005 & -0.340 & -0.256 \\
\hline & std. dev & 0.554 & 0.415 & 0.287 & 0.217 & 0.623 & 0.472 & 0.068 & 0.052 & 1.098 & 0.830 \\
\hline & Q1 & 0.050 & 0.050 & -0.110 & -0.090 & -0.120 & -0.095 & -0.005 & -0.005 & -0.450 & -0.340 \\
\hline & Q2 & 0.130 & 0.110 & 0.010 & 0.010 & -0.030 & -0.020 & 0.001 & 0.001 & -0.050 & -0.050 \\
\hline & Q3 & 0.300 & 0.260 & 0.050 & 0.045 & 0.005 & 0.005 & 0.010 & 0.010 & 0.012 & 0.012 \\
\hline & skew & 2.061 & 2.053 & -2.378 & -2.377 & -2.777 & -2.776 & -1.931 & -2.076 & -2.169 & -2.165 \\
\hline & kurt & 6.650 & 6.686 & 7.869 & 7.906 & 9.613 & 9.603 & 7.425 & 7.665 & 7.579 & 7.557 \\
\hline & & & & & & & & & & & \\
\hline \multirow{7}{*}{ inflation } & mean & -0.029 & -0.042 & -0.009 & -0.023 & -0.003 & -0.004 & 0.006 & 0.008 & 0.039 & 0.076 \\
\hline & std. dev & 0.055 & 0.066 & 0.069 & 0.111 & 0.022 & 0.037 & 0.010 & 0.010 & 0.088 & 0.147 \\
\hline & Q1 & -0.082 & -0.113 & -0.032 & -0.055 & -0.025 & -0.032 & 0.001 & 0.001 & -0.030 & -0.036 \\
\hline & Q2 & -0.010 & -0.026 & -0.011 & -0.032 & -0.005 & -0.008 & 0.003 & 0.004 & 0.031 & 0.034 \\
\hline & Q3 & 0.005 & 0.008 & 0.022 & 0.028 & 0.012 & 0.022 & 0.004 & 0.007 & 0.085 & 0.159 \\
\hline & skew & -0.901 & -0.431 & -1.260 & -1.546 & 0.183 & -0.091 & 2.159 & 1.491 & 0.301 & 0.408 \\
\hline & kurt & 2.709 & 1.584 & 5.053 & 5.850 & 1.830 & 2.015 & 6.638 & 3.755 & 2.539 & 2.406 \\
\hline & & & & & & & & & & & \\
\hline \multirow{7}{*}{ credit } & mean & 1.260 & 1.145 & -0.939 & -0.954 & 1.170 & 1.188 & -0.083 & -0.099 & 1.995 & 1.815 \\
\hline & std. dev & 3.941 & 3.435 & 3.337 & 2.925 & 3.707 & 3.313 & 0.367 & 0.319 & 3.953 & 3.100 \\
\hline & Q1 & -0.145 & -0.135 & -0.850 & -1.115 & -0.235 & -0.250 & -0.160 & -0.175 & 0.010 & -0.010 \\
\hline & Q2 & 0.280 & 0.340 & -0.160 & -0.200 & 0.100 & 0.090 & -0.060 & -0.080 & 0.670 & 0.840 \\
\hline & Q3 & 0.620 & 0.590 & 0.170 & 0.175 & 0.660 & 0.700 & 0.000 & 0.005 & 1.520 & 1.615 \\
\hline & skew & 2.864 & 2.737 & -2.598 & -2.411 & 2.698 & 2.562 & -0.939 & -0.983 & 2.172 & 1.931 \\
\hline & kurt & 9.972 & 9.497 & 9.000 & 8.173 & 9.357 & 8.760 & 5.944 & 5.499 & 6.781 & 5.896 \\
\hline & & & & & & & & & & & \\
\hline \multirow{7}{*}{$\begin{array}{l}\text { house } \\
\text { prices }\end{array}$} & mean & 0.020 & -0.141 & -0.257 & -0.407 & 0.417 & 0.486 & 0.024 & 0.027 & -0.219 & -0.201 \\
\hline & std. dev & 0.876 & 1.694 & 0.632 & 0.967 & 0.760 & 0.654 & 0.046 & 0.067 & 0.503 & 0.986 \\
\hline & Q1 & -0.605 & -1.360 & -0.945 & -1.287 & 0.038 & 0.080 & -0.015 & -0.035 & -0.672 & -1.202 \\
\hline & Q2 & -0.025 & -0.055 & -0.260 & -0.695 & 0.085 & 0.185 & 0.014 & 0.015 & -0.365 & -0.405 \\
\hline & Q3 & 0.550 & 0.797 & 0.055 & 0.153 & 0.253 & 0.542 & 0.033 & 0.070 & -0.005 & 0.008 \\
\hline & skew & -0.812 & -0.976 & -0.279 & -0.027 & 1.510 & 1.242 & 0.643 & -0.273 & 0.186 & 0.540 \\
\hline & kurt & 2.401 & 2.632 & 1.486 & 1.192 & 3.561 & 3.044 & 2.151 & 1.390 & 1.393 & 1.903 \\
\hline & & & & & & & & & & & \\
\hline \multirow{7}{*}{$\begin{array}{l}\text { stock } \\
\text { prices }\end{array}$} & mean & 21.78 & 25.30 & 11.81 & 13.86 & 24.09 & 26.59 & 0.543 & 0.464 & -6.764 & -7.649 \\
\hline & std. dev & 20.05 & 22.16 & 15.43 & 20.09 & 16.73 & 18.37 & 1.903 & 2.143 & 16.17 & 19.29 \\
\hline & Q1 & 8.555 & 9.905 & 2.265 & 2.680 & 10.39 & 11.09 & -0.750 & -1.020 & -20.80 & -19.40 \\
\hline & Q2 & 17.60 & 19.30 & 7.080 & 6.950 & 23.40 & 21.60 & 0.630 & 0.690 & 0.390 & 0.420 \\
\hline & Q3 & 26.05 & 29.10 & 13.85 & 14.20 & 28.85 & 37.60 & 1.475 & 1.760 & 1.095 & 1.445 \\
\hline & skew & 1.343 & 1.072 & 0.861 & 1.038 & 0.469 & 0.395 & -0.453 & -0.852 & -1.025 & -1.159 \\
\hline & kurt & 4.640 & 3.348 & 2.685 & 2.919 & 2.020 & 1.763 & 2.433 & 2.865 & 2.357 & 2.843 \\
\hline
\end{tabular}



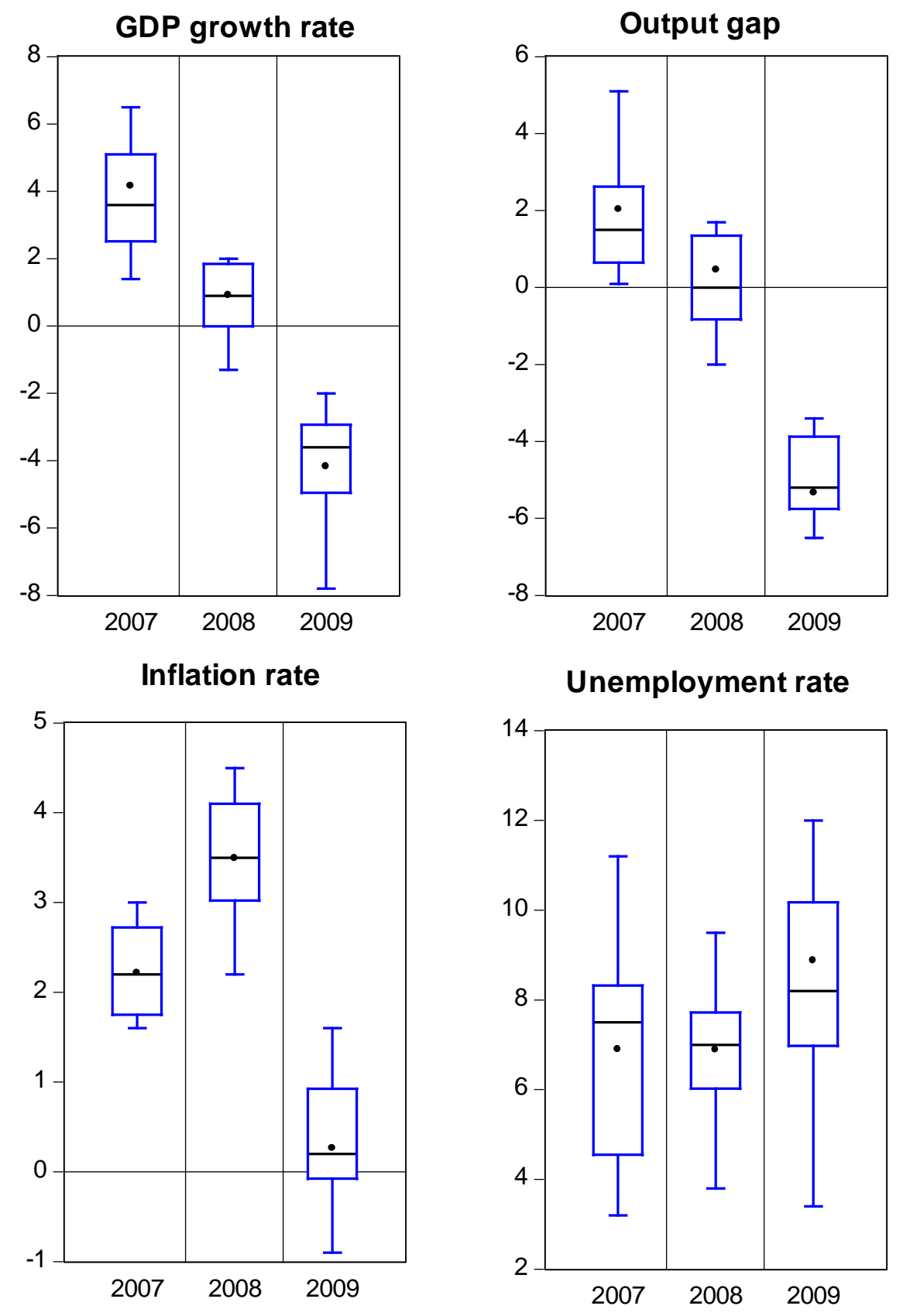

Figure 1. Box plots of the distribution of GDP growth, output gap, inflation rate and unemployment rate in 2007-2009 for 14 euro-area countries.

Note: the box plots in this and the following figures show, for each distrubution, the mean value (represented by a dot), the median value (a straight line), the interquartile range (IQR, containing $50 \%$ of the observations, represented by a box), and the values that are outside the first and third quartiles but within the first (third) quartile minus (plus) 1.5 times the IQR (represented by vertical lines ending with a staple). 

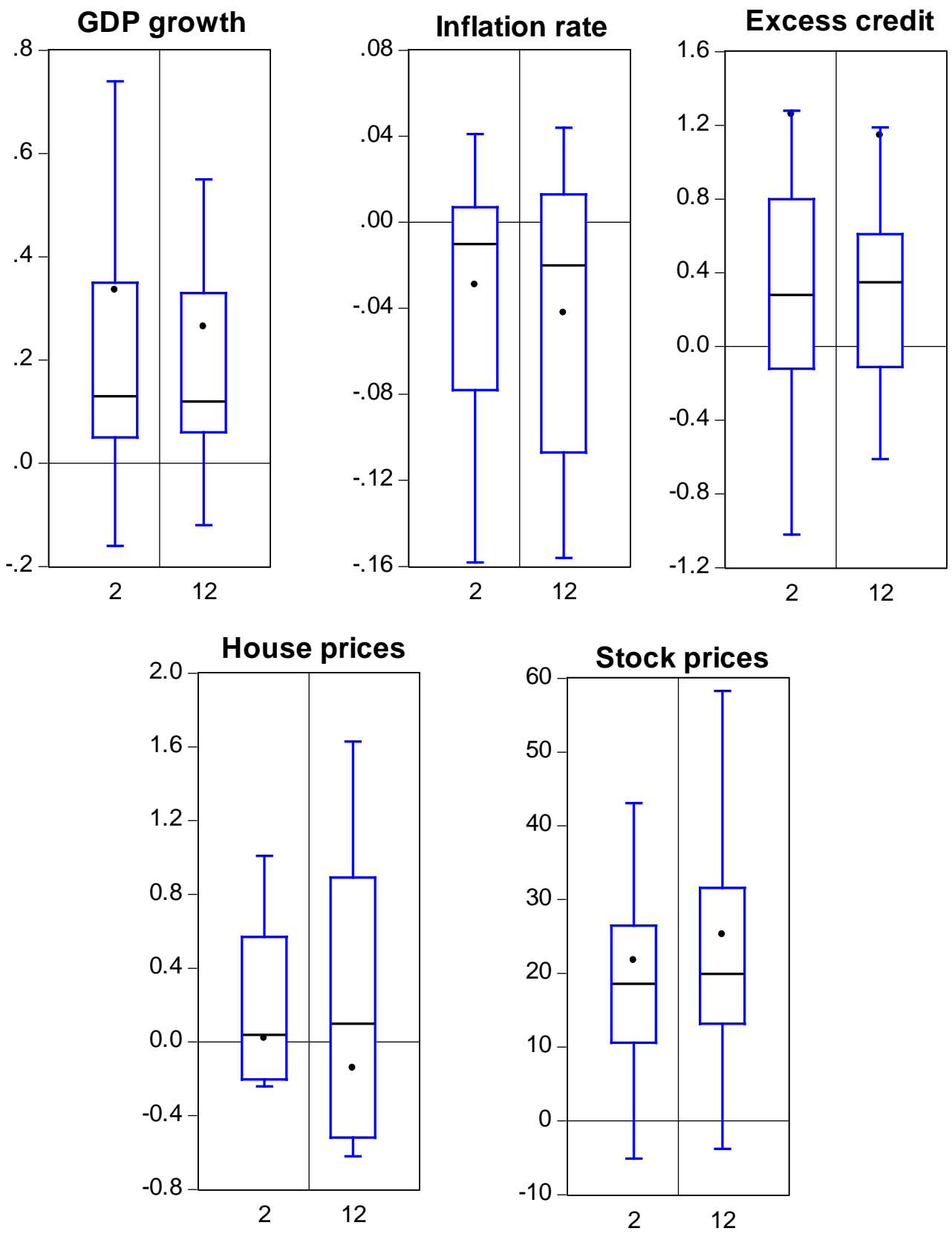

Figure 2. Responses of euro area macro variables to a US output $1 \%$ increase at the 2 - and 12-quarter horizons. 

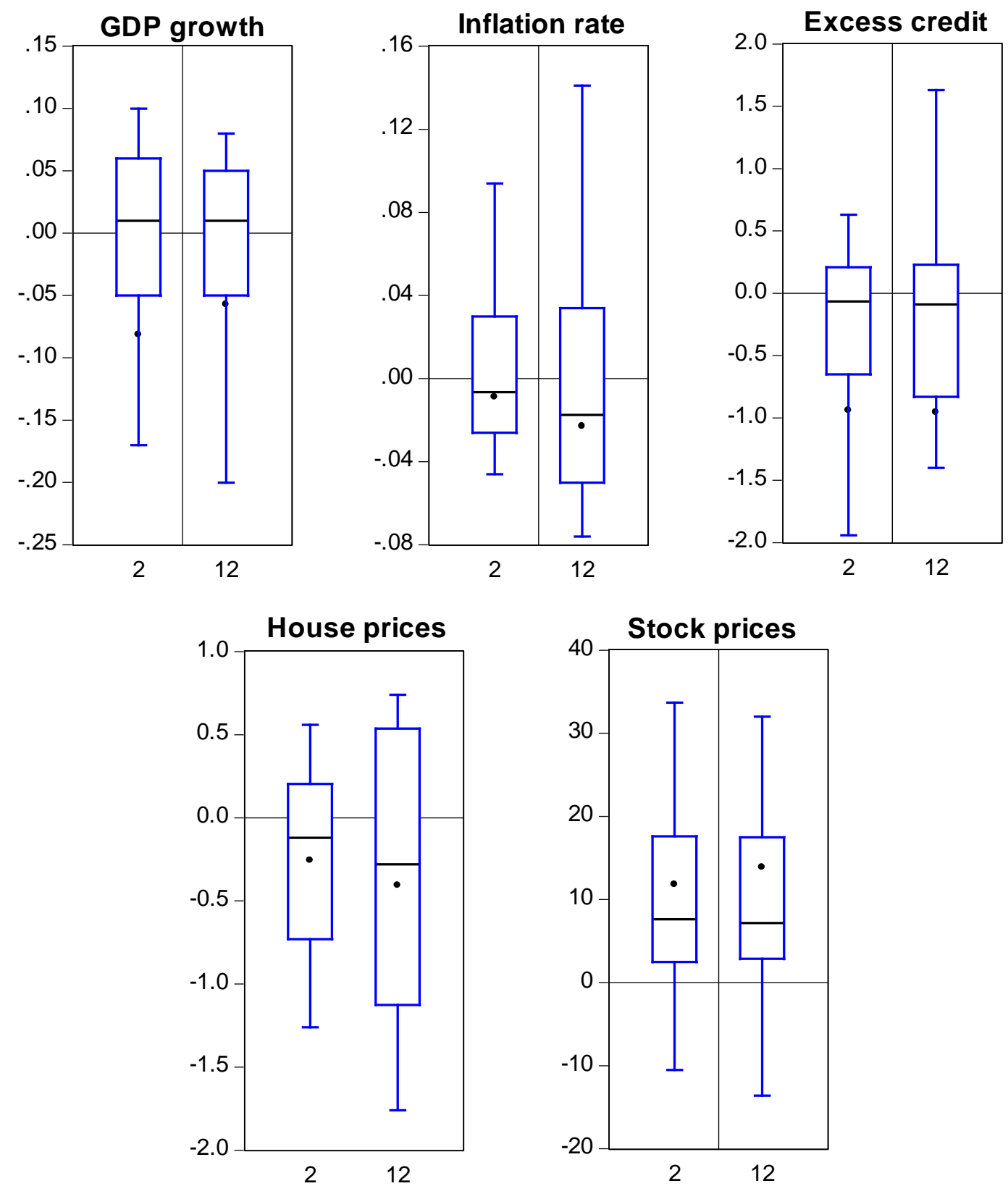

Figure 3. Responses of euro area macro variables to a US excess liquidity $1 \%$ increase at the 2- and 12-quarter horizons. 

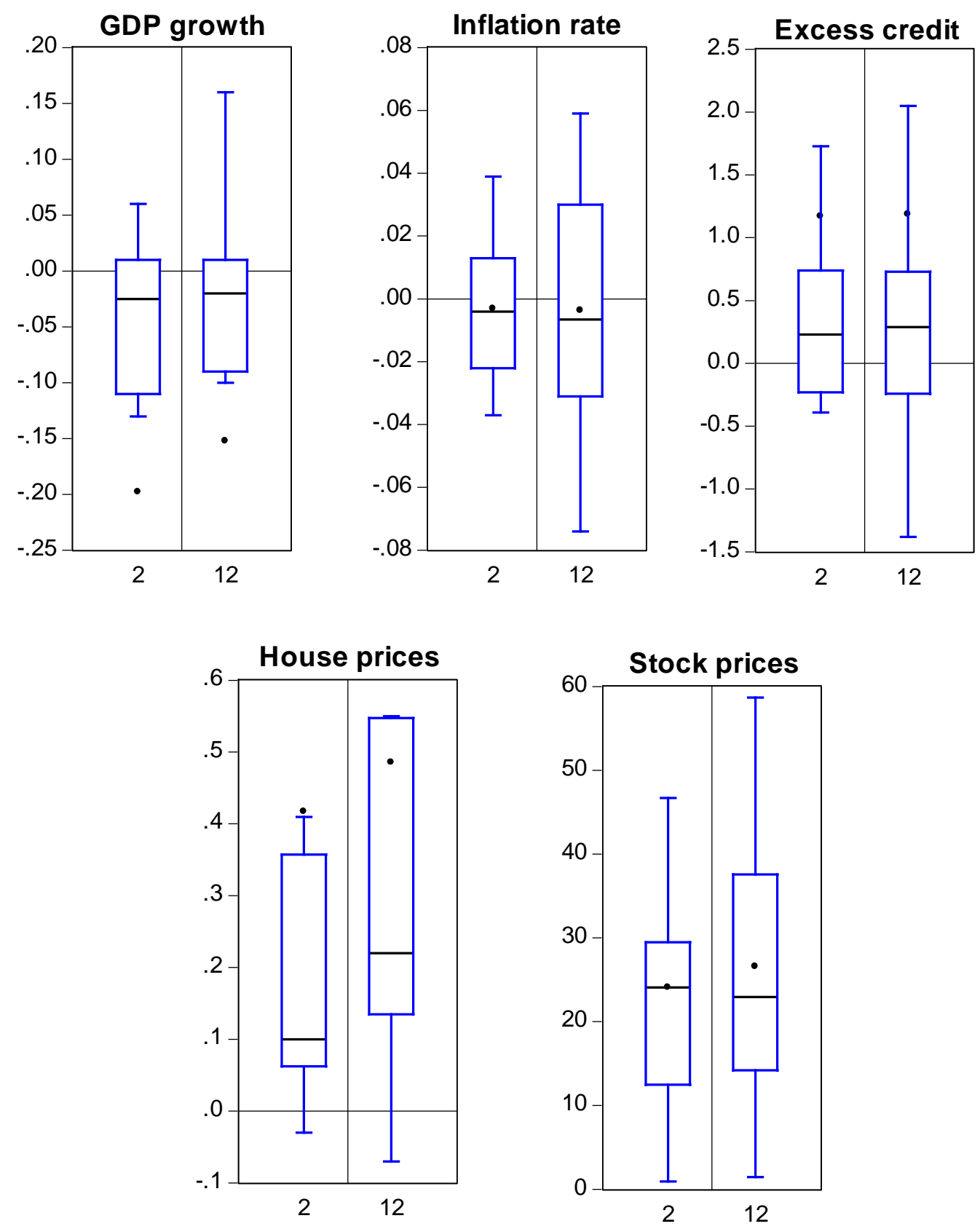

Figure 4. Responses of euro area macro variables to a US house prices $1 \%$ increase at the 2and 12-quarter horizons. 

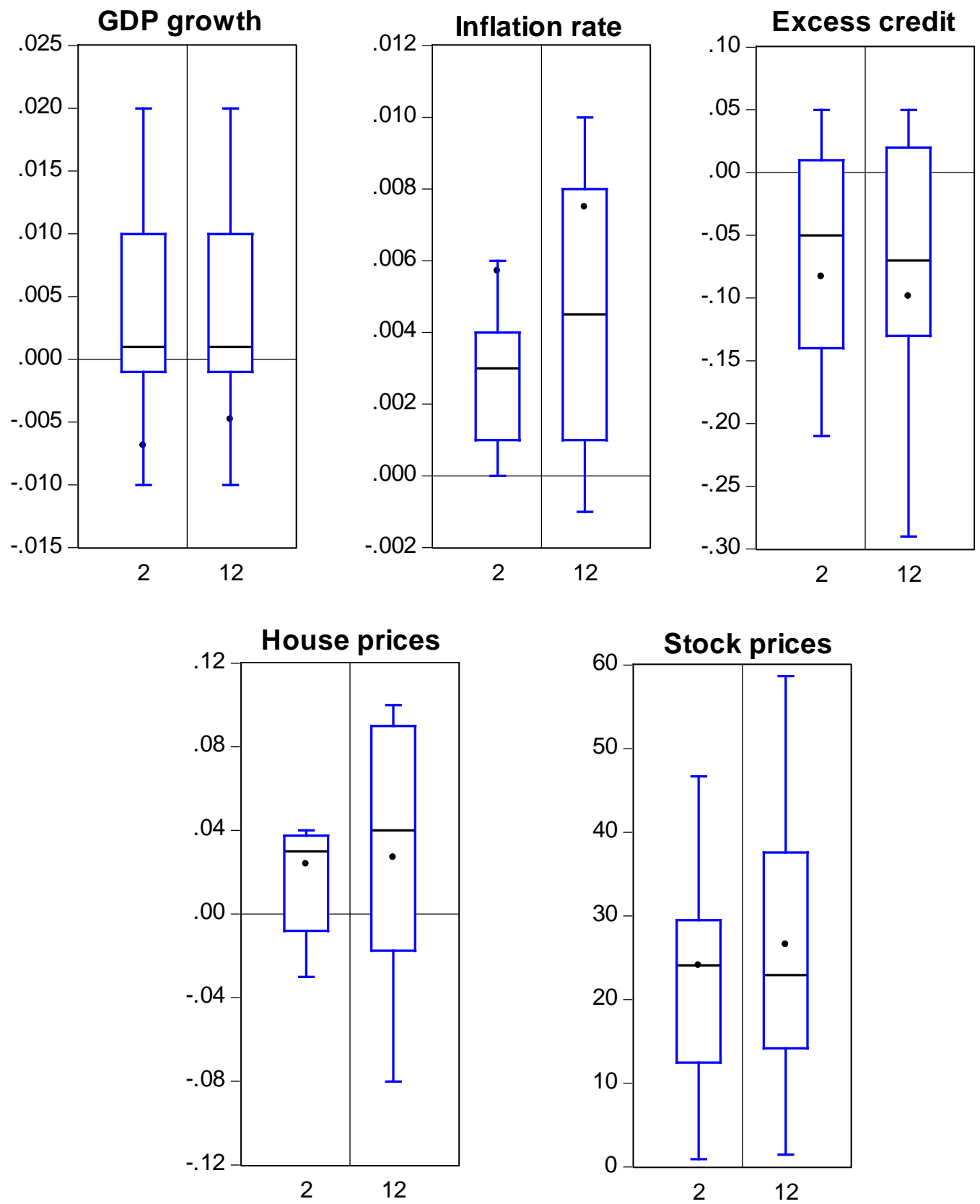

Figure 5. Responses of euro area macro variables to a US stock prices $1 \%$ increase at the 2and 12-quarter horizons. 

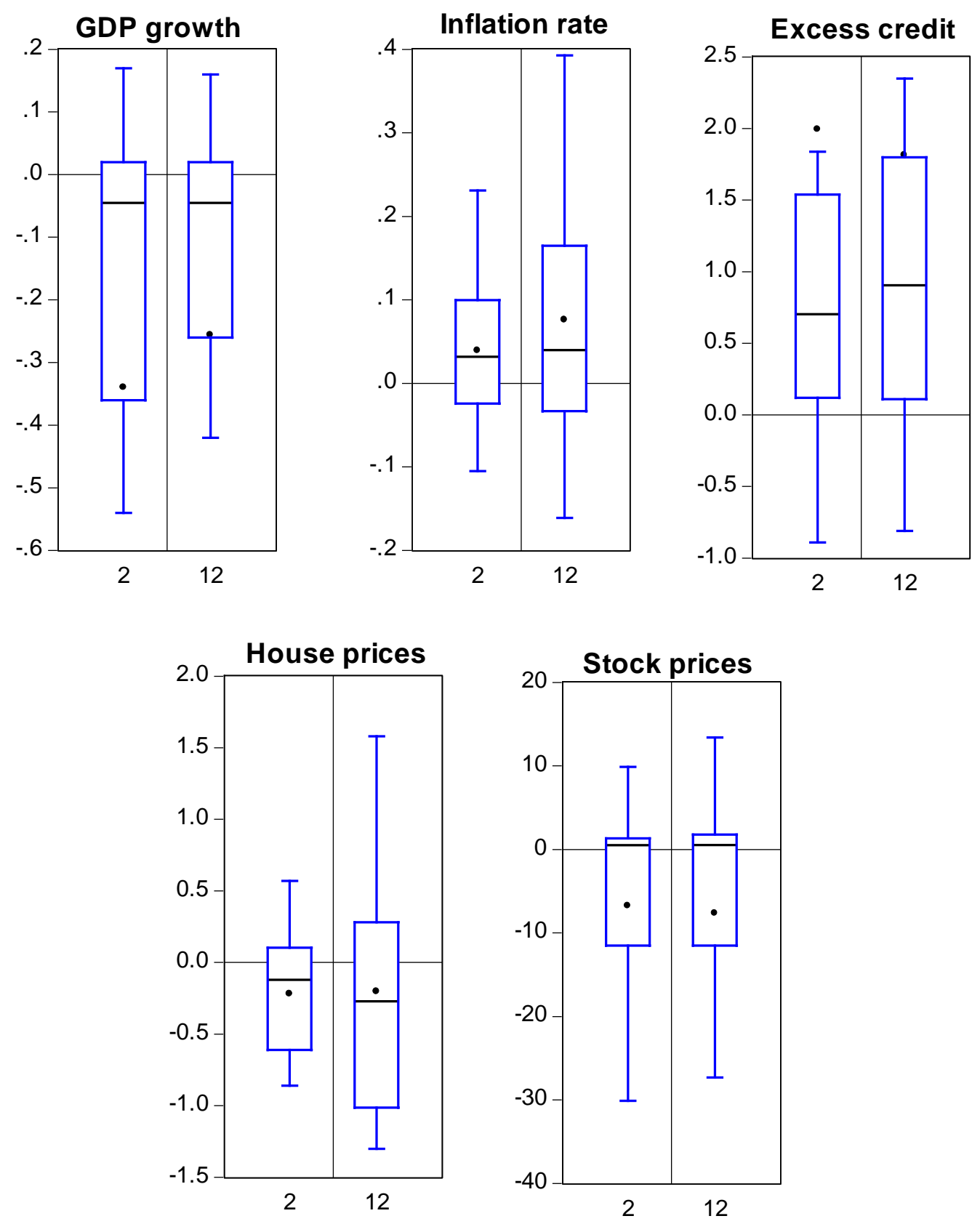

Figure 6. Responses of euro area macro variables to a US financial fragility index $1 \%$ increase at the 2- and 12-quarter horizons. 
DEPARTMENT OF ECONOMICS AND PUBLIC FINANCE "G. PRATO" UNIVERSITY OF TORINO

Corso Unione Sovietica 218 bis - 10134 Torino (ITALY)

Phone: +390116706128 - Fax: +390116706062

Web page: http://eco83.econ.unito.it/prato/ 